\title{
Normoalbuminuric chronic kidney disease in type 1 diabetes: is it real and is it serious?
}

\author{
Vincent Rigalleau $^{1} \cdot$ Laurence Blanco $^{1} \cdot$ Laure Alexandre $^{1} \cdot$ Emilie Pupier $^{1}$. \\ Catherine Lasseur ${ }^{2}$ - Nicole Barthe ${ }^{3}$ - Christian Combe ${ }^{2}$
}

Received: 29 May 2017 / Accepted: 9 June 2017 /Published online: 19 July 2017

(C) Springer-Verlag GmbH Germany 2017

$\begin{array}{ll}\text { Abbreviations } \\ \mathrm{Alb}^{+} & \text {Albuminuric } \\ \mathrm{Alb}^{-} & \text {Non-albuminuric } \\ \mathrm{CKD} & \text { Chronic kidney disease } \\ \text { eGFR } & \text { Estimated GFR } \\ \text { MDRD } & \text { Modification of Diet in Renal Disease } \\ \text { mGFR } & \text { Measured GFR }\end{array}$

To the Editor: We were interested by the recent article by Penno et al, who reported that the majority (17/29) of their participants with stage $\geq 3$ chronic kidney disease (CKD) and type 1 diabetes had the non-albuminuric phenotype ( $\mathrm{Alb}^{-}$; albuminuria $<3.4 \mathrm{mg} / \mathrm{mmol}$ ) [1]; this is an unexpectedly high proportion. As reported by the authors, these participants had higher Modification of Diet in Renal Disease (MDRD) Study equation-estimated GFR (eGFR) $\left(52 \pm 7 \mathrm{ml} \mathrm{min}^{-1}[1.73 \mathrm{~m}]^{-2}\right)$ vs those with the albuminuric phenotype $\left(\mathrm{Alb}^{+}\right.$; albuminuria $\geq 3.4 \mathrm{mg} / \mathrm{mmol}$ ), who had an eGFR of $45 \pm 11 \mathrm{ml} \mathrm{min}^{-1}$ $[1.73 \mathrm{~m}]^{-2}(p<0.05)$; this was not commented on to a great extent in the article. Two hypotheses may explain this less advanced renal failure in the $\mathrm{Alb}^{-}$group.

First, participants with $\mathrm{Alb}^{-}$phenotype may not really have CKD. Although it works better than the old Cockcroft and Gault formula [2], the MDRD equation was built by multiple regression analysis from a population with renal insufficiency,

Vincent Rigalleau

vincent.rigalleau@chu-bordeaux.fr

1 Nutrition-Diabétologie, Hôpital Haut-Lévêque, Avenue de Magellan, 33600 Pessac, France

2 Université de Bordeaux, Victor Segalen, Bordeaux, France

3 Médecine Nucléaire, Hôpital Pellegrin, Bordeaux, France and it is well-known to underestimate normal and high GFR: according to the analysis from Froissard et al, $20.5 \%$ of MDRD equation-estimated stage 3 CKD was, in fact, stage 2 CKD based on ${ }^{51} \mathrm{Cr}$-EDTA analysis [3]. Penno et al recognised that estimation by the MDRD equation was a limitation of their study [1].

To investigate whether the higher MDRD equationdeduced eGFR in the $\mathrm{Alb}^{-}$group might have resulted from such underestimated eGFR, we compared the MDRD equation-eGFR to isotopically measured GFR (mGFR), analysed using ${ }^{51} \mathrm{Cr}$-EDTA, in 40 individuals with type $1 \mathrm{di}$ abetes and MDRD equation-eGFR below $60 \mathrm{ml} \mathrm{min} \mathrm{min}^{-1}$ $[1.73 \mathrm{~m}]^{-2}$. Participants included 21 men $(52.5 \%)$ aged $57 \pm 13$ years old, with a median albumin excretion rate (AER) of $189 \mathrm{mg} / 24 \mathrm{~h}$ (range 5-2500). Only three individuals had the $\mathrm{Alb}^{-}$phenotype. In our participants, the MDRD equation-eGFR was $41.7 \pm 12.4 \mathrm{ml} \mathrm{min}^{-1}[1.73 \mathrm{~m}]^{-2}$, which was similar to the mGFR $\left(42.0 \pm 21.9 \mathrm{ml} \mathrm{min}^{-1}[1.73 \mathrm{~m}]^{-2}\right)$. Regarding eGFR, individuals with stage 3 a CKD in our study $(n=22)$ were similar to the individuals with stage 3 CKD in the study by Penno et al [1], and their MDRD equation-eGFR did not differ from mGFR (MDRD equation-eGFR: $51.1 \pm 3.7 \mathrm{ml} \mathrm{min}^{-1}[1.73 \mathrm{~m}]^{-2}$; mGFR: $50.7 \pm 15.1 \mathrm{ml} \mathrm{min}^{-1}$ $[1.73 \mathrm{~m}]^{-2}$ ) (unpublished results, V. Rigalleau).

As demonstrated using data from the DCCT, in the 60-80 ml min ${ }^{-1}[1.73 \mathrm{~m}]^{-2}$ MDRD equation-eGFR range, $\sim 80 \%$ of eGFR values may be underestimated by more than $20 \mathrm{ml} \mathrm{min}{ }^{-1}[1.73 \mathrm{~m}]^{-2}$ as compared with the iothalamate clearance method [4]. This may explain the large number of individuals with MDRD equation-eGFR 60-74 $\mathrm{ml} \mathrm{min}^{-1}$ $[1.73 \mathrm{~m}]^{-2}$ in Penno et al's study who were categorised as $\mathrm{Alb}^{-}(n=63) \mathrm{vs} \mathrm{Alb}^{+}(n=8)$. However, this does not seem to explain the high number of individuals with the $\mathrm{Alb}^{-}$ phenotype with stage $3 \mathrm{CKD}$, who were probably highly renal insufficient. 
The second hypothesis is that the higher eGFR in individuals with the $\mathrm{Alb}^{-}$phenotype with stage $3 \mathrm{CKD}$ may, in fact, reflect less progressive renal failure, which seemed to be overlooked by Penno et al; although, in their conclusion, they did state that their findings 'support the hypothesis of 'two distinct pathways ( $\mathrm{Alb}^{-}$and $\mathrm{Alb}^{+}$) both potentially progressing to advanced kidney disease', referring to the possibility of progressive renal decline with the $\mathrm{Alb}^{-}$phenotype [5]. It should not be forgotten that progressive renal decline is three to five times more frequent in individuals with type 1 diabetes and albuminuria. Ten years ago, in individuals with type 2 diabetes (75\%) and type 1 diabetes $(25 \%)$, we reported that $17 \%$ with MDRD equation-eGFR below $60 \mathrm{ml} \mathrm{min}^{-1}[1.73 \mathrm{~m}]^{-2}$ were normoalbuminuric [6]. As with the participants in Penno et al's study, the MDRD equation-eGFR was found to be $5 \mathrm{ml} \mathrm{min}$ min $^{-1}$ $[1.73 \mathrm{~m}]^{-2}$ higher in individuals with normoalbuminuria vs those with albuminuria. By contrast with those with albuminuria, individuals with normoalbuminuria did not progress to dialysis or death during the 3 year follow-up [6]. Whether these individuals are more prone to cardiovascular events and mortality, as reported for type 2 diabetes [7, 8], is another important question. In another study (unpublished results, V. Rigalleau), of the 243 individuals with type 1 diabetes followed by our research team in Bordeaux, France, 35 had MDRD equation-eGFR below $60 \mathrm{ml} \mathrm{min}^{-1}[1.73 \mathrm{~m}]^{-2}$, and the history of cardiovascular events were similarly prevalent in the 19 individuals in the $\mathrm{Alb}^{+}$group $(n=5,26 \%)$ and the 16 individuals in the $\mathrm{Alb}^{-}$group $(n=4,25 \%)$. We speculate whether the 10 out of 29 participants with stage $\geq 3$ CKD in Penno et al's study who also had previous cardiovascular events (as reported in Table 1 in their article) were also similarly distributed between the $\mathrm{Alb}^{-}$and $\mathrm{Alb}^{+}$group. Further longitudinal studies will be required to determine whether $\mathrm{Alb}^{-} \mathrm{CKD}$ seriously progresses to cardiovascular events, dialysis or death in type 1 diabetes.
Funding This work received no specific grant from any funding agency in the public, commercial or not-for-profit sectors.

Duality of interest The authors declare that there is no duality of interest associated with this manuscript.

Contribution statement All authors were responsible for drafting the article and revising it critically for important intellectual content. All the authors approved the version to be published.

\section{References}

1. Penno G, Russo E, Garofolo M et al (2017) Evidence for two distinct phenotypes of chronic kidney disease in individuals with type 1 diabetes mellitus. Diabetologia 60:1102-1113

2. Rigalleau V, Lasseur C, Perlemoine C et al (2005) Estimation of glomerular filtration rate in diabetic patients, Cockcroft or MDRD formula? Diabetes Care 28:838-843

3. Froissard M, Rossert J, Jacquot C et al (2005) Predictive performance of the modification of diet in renal disease and Cockcroft-Gault equations for estimating renal function. J Am Soc Nephrol 16:763-773

4. Ibrahim H, Mondress M, Tello A et al (2005) An alternative formula to the Cockcroft-Gault and the modification of diet in renal diseases formulas in predicting GFR in individuals with type 1 diabetes. J Am Soc Nephrol 16:1051-1060

5. Krolewski AS (2015) Progressive renal decline: the new paradigm of diabetic nephropathy in type 1 diabetes. Diabetes Care 38:954-962

6. Rigalleau V, Lasseur C, Raffaitin C et al (2007) Normoalbuminuric renal insufficient diabetic patients: a lower risk group. Diabetes Care 30:2034-2039

7. Afkarian M, Sachs MC, Kestenbaum B et al (2013) Kidney disease and increased mortality risk in type 2 diabetes. J Am Soc Nephrol 24: 302-308

8. Eunyoung L, Hyung JO, Jung TP et al (2016) The incidence of cardiovascular events is comparable between normoalbuminuric and albuminuric diabetic patients with chronic kidney disease. Medicine 95:e3175 